\title{
Modeling for the Compactness of Urban Spatial Form
}

\author{
Rui Wang ${ }^{1, a, *}$ \\ ${ }^{1}$ School of North China Electric Power University Baoding, Baoding 071000, China. \\ a72770@163.com
}

\begin{abstract}
With the continuous development of social modernization, the requirements for urban land resources become increasingly urgent. Considering that there is no specific measurement of the compactness of urban spatial form, this paper set up a new model, which graphically defines the concept of population layers to simulate the average height of the city. In this way, when the urban population grows, the city will ease the pressure on land resources by increasing the height rather than outward expansion. This is an idealized model, but it can be used to evaluate the urban compactness efficiently to a certain extent.
\end{abstract}

Keywords: Compact design, land utilization, urban spatial form.

\section{Introduction}

Compact design means making more efficient use of land that has already been developed. However, in the process of urban smart growth in the new century, we must avoid the city's sprawling. Accordingly, with the increasing population density, we should advocate development to grow up, rather than out, thus making the most of public investment [1]. Based on the viewpoint above, this model visualizes the cases when the city population continuously grows, and proposes a method for evaluating the compactness of urban spatial form.

\section{Model Elaboration}

Supposing that all the people are uniformly standing on the urban areas already developed, which ensures that the population is evenly distributed. This is an ideal situation, but can explain the model graphically. When urban population grows, so too does the population density, we increase the number of the people layers to accommodate more people successfully without expanding the city's boundary, that is, we enlarge the compactness of urban spatial form by increasing the average height of urban space.

The model can be illustrated in the following figures.

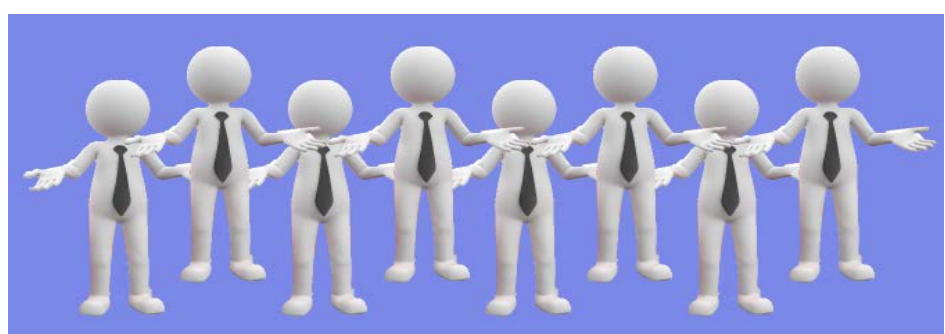

Fig 1. The compactness of urban spatial form is low 
Then we increase the population density by increasing the average height of urban space, under the premise of adequate housing area per capita.

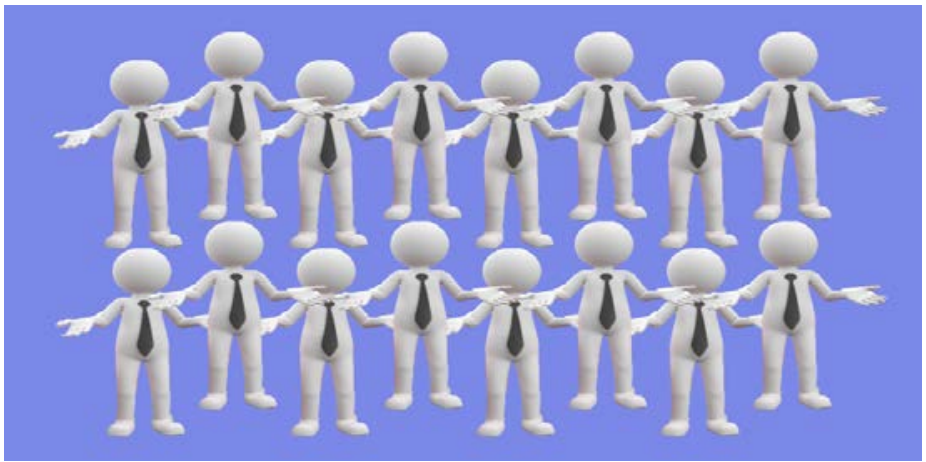

Fig 2. The compactness of urban spatial form is general Similarly, we can further increase the layers.

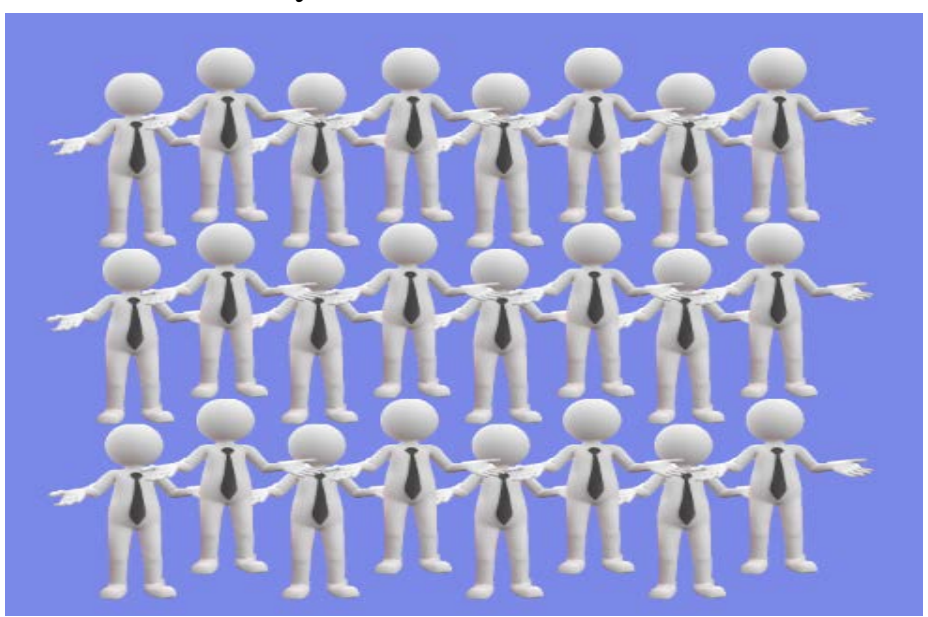

Fig 3. The compactness of urban spatial form is high

So we can draw the following conclusions:

To some extent, the average height of urban space represents the compactness of urban spatial form.

in which,

$$
\begin{gathered}
H=\frac{C_{\alpha}}{L A} \\
L A=\frac{B A}{B P} \\
B_{\alpha}=k \times H
\end{gathered}
$$

$H$ is Average height of urban space

$L A$ is Per capita land area

$B A$ is Total area of urban built-up area

$B P$ is Total population of urban built-up area

$k$ is a constant. We might as well set $k=10$.

This paper discusses the system based on graphic method

\section{Conclusions}

This paper discusses a model to measure the compactness of urban spatial form. The specific work is as follows:

(1) Analyze and compare the relationship between the urban population growth and the compactness.

(2) Simulate the average height by defining the people layers to estimate the solution to the constant 
population growth in the city.

(3) Quantify the compactness of urban spatial form by formula establishment.

In short, it is scientific to evaluate the compactness of urban spatial form through this graphical method. New definitions have been generated, and they can be applied to assess some certain characteristics of urban morphology and urban development. Last but not least, under the premise of ensuring the per capita housing area, this model can fully evaluate the current population capacity.

\section{References}

[1] All about China. "Five evaluation indexes of urban sustainable development." China Economy. <http://www.jiemian.com/article/631163.html> (accessed 2 May, 2016) 